\title{
Epistaksis ile Başvuran Olgularda Kanama Diyatezi Oranı ve Pediatrik Kanama Skorunun Tanıdaki Değeri
}

\section{The Diagnostic Value of Bleeding Diathesis Rate and Pediatric Bleeding Score in Patients Presenting with Epistaxis}

\author{
Nergiz Öner ${ }^{1}$, Gürses Şahin ${ }^{1}$, Şule Yeşil ${ }^{1}$, Burçak Kurucu Bilgin¹, Emre Çapkınoğlu¹, Azize Ceren Kılcı ${ }^{1}$, \\ Şeyma Ünüvar Gök ${ }^{1}$, Ali Fettah ${ }^{1}$
}

'Sağlık Bilimleri Üniversitesi, Dr. Sami Ulus Kadın Doğum, Çocuk Sağlığı ve Hastalıkları Eğitim ve Araştırma Hastanesi, Çocuk Hematoloji ve Onkoloji, Ankara, Türkiye

Yazışma Adresi: Nergiz Öner, Sağlık Bilimleri Üniversitesi, Dr. Sami Ulus Kadın Doğum, Çocuk Sağlığı ve Hastalıkları Eğitim ve Araştırma Hastanesi, Çocuk Hematoloji ve Onkoloji, Ankara, Türkiye

e-mail: nbattaloglu@yahoo.com

Geliş Tarihi/Received: 25 Şubat 2021 Kabul Tarihi/Accepted: 9 Nisan 2021

\begin{abstract}
Öz
Amaç: Epistaksis çocukluk yaş grubunda sık görülen bir durumdur. Ancak bu şikayet ile başvuran çocuklarda altta yatan kanama bozukluklarına tanı konulması önemlidir. Hastalarda kanama bozukluğu olup olmadığını belirlemek için birinci basamak sağlık hizmetlerinde kullanılacak basit yöntemlere ihtiyaç vardır. Bu çalışmanın amacı, epistaksis ile başvuran hastaları pediatrik kanama anketi ile değerlendirmek ve semptomatik ancak başlangıç hemostatik testleri normal olan hastaların tanısal değerini belirlemektir. Hastalar ve Yöntem: Çalışma, prospektif olarak Ekim 2020-Aralık 2020 tarihleri arasında gerçekleştirildi. Çalışma için etik kurul onayı alındı. Çalışma grubuna burun kanaması olan 77 çocuk, kontrol grubuna 20 sağlıklı çocuk dahil edildi. Değerlendirme için Pediatrik Kanama Anketi (PBQ) kullanıldı.

Bulgular: Çalışmamızda hastaların \% 19,4'üne $(n=15)$ kanama diyatezi ( $($ Wh: 10, nadir faktör eksikliği: 5) tanısı konuldu. Hastaların ortalama başvuru yaşı 8,99 $\pm 3,42$ (3-17) yıldı. 37'si (\%48) kız, 40'ı erkekti. PBQ epistaksis skoru açısından kanama diyatezi olanlar ve olmayanlar arasında istatistiksel olarak fark yoktu, genel skor istatistiksel olarak farklı olmamakla birlikte kanama diyatezi olan grupta daha yüksekti $(p>0,05)$. Kutanöz kanama skoru kanama diyatezi olan grupta daha yüksekti ve istatistiksel olarak anlamlı fark vardı $(p: 0,004)(E D: 0,62)$

Sonuç: Bu çalışma, birinci basamak sağlık kuruluşlarına başvuran epistaksisli hastalarda pediatrik kanama anketinin kullanılabileceğini ve yüksek genel skor ve kutanöz kanama skorlu hastalardan ileri araştırmalar için hematoloji konsültasyonu istenmesi gerektiğini göstermiştir.

Anahtar Kelimeler: Epistaksis, kanama bozukluğu, kanama skoru

Abstract

Aim: Epistaxis is a common condition in the childhood age group. However, it is important to diagnose the underlying bleeding disorders in children presenting with this complaint. Simple methods to be used in primary health care are needed to determine whether patients have bleeding disorders. This study aims to evaluate patients presenting with epistaxis with the bleeding questionnaire and determine the diagnostic value of patients with symptomatic but normal hemostatic tests.

Patients and Methods: The study was performed prospectively between October 2020 and December 2020. The study was approved by the institutional review board of the local ethics committee. Seventyseven children with epistaxis were included in the study group and 20 healthy children in the control group. Pediatric Bleeding Questionnaire $(P B Q)$ was used for evaluation.

Results: In our study, $19.4 \%(n=15)$ of the patients were diagnosed with bleeding diathesis (vWh: 10, rare factor deficiency: 5 ). The mean age at presentation was $8.99 \pm 3.42(3-17)$ years. Thirty-seven $(48 \%)$ were girls and 40 were boys. In terms of PBQ epistaxis score, there was no statistically significant difference between those with and without bleeding diathesis. However, the overall score was not statistically different; it was higher in the group with bleeding diathesis. The cutaneous bleeding score was higher in the group with bleeding diathesis and there was a statistically significant difference. Conclusions: This study showed that bleeding scores can be used in patients with epistaxis who apply to primary health care institutions and patients with high overall scores and cutaneous bleeding scores should be directed to the hematologist for further research.Keywords: Epistaxis, bleeding diathesis, bleeding score
\end{abstract}

Key words: Epistaxis, bleeding disorders, bleeding score

Atıf yapmak için: Öner N, Şahin G, Yeşil Ş, Kurucu Bilgin B, Çapkınoğlu E,Kılcı AC, Ünüvar Gök Ş, Fettah A. Epistaksis ile Başvuran Olgularda Kanama Diyatezi Oranı ve Pediatrik Kanama Skorunun Tanıdaki Değeri. Selcuk Med J 2021;37(2): $124-129$

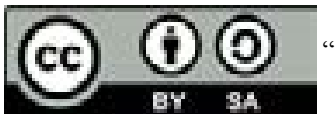

Açıklama: Yazarların hiçbiri, bu makalede bahsedilen herhangi bir ürün, aygıt veya ilaç ile ilgili maddi çıkar iliş̧kisine sahip değildir. Araştırma, herhangi bir dış organizasyon tarafından desteklenmedi. Yazarlar çalışmanın birincil verilerine tam erişim izni vermek ve derginin talep ettiği takdirde verileri incelemesine izin vermeyi kabul etmektedirler. 


\section{GíRiş}

Epistaksis (burun kanaması) çocuklarda sık görülür. En sık görüldüğü yaş 2-10 yaş, ortalama başvuru yaşı ise 7-9 yaştır $(1,2)$. Beş yaş altı çocukların \%30'u, 6-10 yaş arasındakilerin \%56'sında hayatları boyunca en az bir kez burun kanaması görülür (3). Genellikle çocukluk yaş grubunda en sık görülen nedenleri travma ve inflamasyondur (4). Epistaksisli pediatrik olgularda kanama diyatezi oranı \% 8-20 arasında değişir (5). Burun kanaması nedeni ile başvuran hastaların sağlıklı mı yoksa hafif kanama bozukluğuna sahip hastalar mı olduğunu ayırmak güçtür. Hastalarda kanama bozukluğu olup olmadığını belirlemek için birinci basamak sağlık hizmetlerinde kullanılacak basit yöntemlere intiyaç vardır.

Kanama bozukluklarında tanıya ulaşmada detaylı ve doğru kanama öyküsü elde edilerek standardize kanama anketleri geliştirilmiştir. Bunlardan biri çocukluk yaş grubu için geliştirilen Pediatrik Kanama Anketi (PBQ)'dir (6-9). PBQ bu konuda deneyimli hekimler tarafından uygulanan bir ankettir. Son yıllarda hastaların ve ailelerinin kendi kendine uygulayabileceği anketler geliştirilmiştir. Casey et al. (10) 2017 yılında 12 yaş üstü hastaların ve ailelerinin yapabileceği bir kanama anketi geliştirmiştir. Bui et al. (11) 2019 yılında 8-12 yaş arası hastaların minumum aile yardımı ile uygulayabilecekleri bir anket geliştirmiş ve kanama diyatezlerinin belirlenmesinde etkin olarak kullanılabileceğini belirtmişlerdir. Ancak hem hekimler tarafından uygulanan hem de hastaların kendi kendine uyguladıkları anketler kullanılarak epistaksisli çocuklarda yapılan araştırmalar sınırlıdır.

Çalışmanın amacı, epistaksis ile başvuran olguların pediatrik kanama anketi ile değerlendirilmesi, semptomatik olan ancak başlangıç hemostatik testleri normal saptanan olguları ayırımındaki tanısal değerinin belirlenmesidir.

\section{HASTALAR VE YÖNTEM Hasta Grubu}

Çalışma, prospektif olarak Ekim 2020-Aralık 2020 tarihleri arasında gerçekleştirildi. Çalışmaya Çocuk Hematoloji Polikliniği'ne epistaksis nedeni ile konsülte edilen 3-18 yaş arası 77 hasta alındı. Hastaların hiçbirinin daha önceden tanı konulmuş bir kanama hastalığı yoktu. Kontrol grubu olarak preoperatif değerlendirme için genel çocuk polikliniğine konsülte edilen 20 hasta alındı. Hastalar kanama diyatezi olan epistaksisli hastalar (grup 1, n:15 (\%15)), kanama diyatezi olmayan epistaksisli hastalar (grup 2, n:62 (\%64)) ve sağlıklı kontrol grubu (grup 3, n:20 (\%21)) olarak 3 gruba ayrıldı.

Çalışma Helsinki Deklarasyon ilkelerine uygun olarak yapılmıştır. Dr. Sami Ulus Kadın Doğum Çocuk Sağlığı ve Hastalıkları Eğitim ve Araştırma Hastanesi Klinik Araştırmalar Etik Kurulu'ndan çalışma için etik kurul onayı alınmıştır (Etik kurul numarası E-20/1012). Helsinki Deklarasyonu'nun en son versiyonuna göre tüm hastaların ebeveynlerinden bilgilendirilmiş onam alındı.

\section{Pediatrik Kanama Anketinin Uygulanması}

Hastaları değerlendirmek için Bowman et al. (69) 2009 yılında yayınladığı kanama semptomlarının varlığını ve ciddiyetini değerlendiren Pediatrik Kanama Anketi (PBQ) kullanıldı. Bu kanama anketi burun kanaması, kutanöz kanamalar, minör yaralanmalar, ağız içi kanaması, gastrointestinal sistem kanamaları, diş çekimi, cerrahi sonrası kanamalar, menoraji, postpartum kanama, hemartroz, kas hematomu ve santral sinir sistemi (SSS) kanamaları, sünnet sonrası kanama, göbek kanaması, sefal hematom, makroskopik hematüri, girişim yeri kanaması, konjunktival kanamalardan oluşan diğer kanamaları içermektedir. Skor cerrahi sonrası ve diş çekimi sonrası kanamalarda -1 (en az iki kez yapılan işlemde kanama olmaması) ile 4 (transfüzyon, faktör konsantresi, desmopressin tedavisi uygulanması), postpartum kanamalarda -1 ile 3, diğer kanamalarda ise kanama şiddetine göre 0 (kanama olmaması veya nadir kanama görülmesi) ile 3-4 (transfüzyon, faktör konsantresi, desmopressin tedavisi uygulanması) puan arasında değişmektedir (Tablo-1). PBQ, epistaksisli 77 hastaya ve kontrol grubuna yüz yüze bir pediatrik hematolog tarafından uygulandı. Poliklinik kontrollerinde yazılı onam alındıktan sonra yüz yüze çalışma doktoru tarafından kanama öyküsü alınarak kanama skorları hesaplandı.

\section{Laboratuvar Metodları ve Tanı Kriterleri}

Epistaksis nedeni ile konsülte edilen hastaların ilk değerlendirmesi, ayrıntılı bir kişisel ve ailede kanama öyküsü, fizik muayene, trombosit sayısı ve morfolojisi/ kanama zamanı, protrombin zamanı (PT), aktive parsiyel tromboplastin zamanı (aPTT) ve fibrinojen düzeyi alınarak yapıldı. Gerekli görülen hastalarda von Willebrand faktör antijeni (vWf: Ag), von Willebrand faktör ristocetin kofaktör aktivitesi (vWf: Rco), faktör (F) VIII:C seviyeleri ve pıhtı erime testinden oluşan kapsamlı bir hemostaz tarama paneli, PT ve aPTT testlerinde bozukluk olan hastalarda sonuçlara göre pıhtılaşma faktörü seviyeleri ölçüldü. Pıhtılaşma faktörü eksikliklerinin teşhisi için kesme değerleri FVII, FVIII, FIX, XI için <0.40iu / mL ve fibrinojen için 
Tablo 1. Pediatrik Kanama Anketi

\begin{tabular}{|c|c|c|c|c|c|c|}
\hline $\begin{array}{l}\text { Skor } \\
\text { Semptom }\end{array}$ & -1 & 0 & 1 & 2 & 3 & 4 \\
\hline \multicolumn{7}{|l|}{ Burun } \\
\hline kanaması & - & $\begin{array}{l}\text { Yok/nadir } \\
(<5 / \text { yıl })\end{array}$ & $\begin{array}{l}\text { >5/yıl veya } \\
>10 \text { dakika }\end{array}$ & $\begin{array}{l}\text { Konsültasyon } \\
\text { istenmiş }\end{array}$ & $\begin{array}{l}\text { Tampon/koter } \\
\text { antifibrinolitik }\end{array}$ & $\begin{array}{l}\text { transfüzyon/replasman } \\
\text { tedavisi/desmopressin }\end{array}$ \\
\hline \multicolumn{7}{|l|}{ Kutanöz } \\
\hline kanama & - & $\begin{array}{l}\text { Yok/nadir } \\
(<1 \mathrm{~cm})\end{array}$ & $\begin{array}{l}\text { Travmasız } \\
>1 \mathrm{~cm}\end{array}$ & $\begin{array}{l}\text { Konsültasyon } \\
\text { istenmiş }\end{array}$ & & \\
\hline Minor yara & - & $\begin{array}{l}\text { Yok/nadir } \\
(<5 / \text { yıl })\end{array}$ & $\begin{array}{l}>5 / \text { yıl veya } \\
>5 \text { dakika }\end{array}$ & $\begin{array}{l}\text { Konsültasyon } \\
\text { istenmiş }\end{array}$ & $\begin{array}{l}\text { Cerrahi hemosta } \\
\text { antifibrinolitik }\end{array}$ & $\begin{array}{l}\text { az/ Transfüzyon/replasman } \\
\text { tedavisi/desmopressin }\end{array}$ \\
\hline \multicolumn{7}{|c|}{ 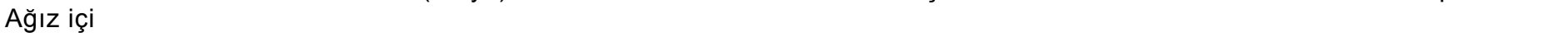 } \\
\hline kanaması & - & Yok & $\begin{array}{l}\text { En az } 1 \mathrm{kez} \\
\text { bildirilmiş }\end{array}$ & $\begin{array}{l}\text { Konsültasyon } \\
\text { istenmiş }\end{array}$ & \multicolumn{2}{|c|}{$\begin{array}{ll}\text { Cerrahi hemostaz/ } & \text { Transfüzyon/replasman } \\
\text { antifibrinolitik } & \text { tedavisi/desmopressin }\end{array}$} \\
\hline Gis kanaması & - & Yok & $\begin{array}{l}\text { Neden } \\
\text { belirlenmiş }\end{array}$ & $\begin{array}{l}\text { Konsültasyon } \\
\text { istenmiş/ } \\
\text { spontan }\end{array}$ & \multicolumn{2}{|c|}{$\begin{array}{l}\text { Cerrahi hemostaz/ } \\
\text { Antifibrinolitik } \\
\text { /transfüzyon/ } \\
\text { Desmopressin/ } \\
\text { replasman tedavisi }\end{array}$} \\
\hline $\begin{array}{l}\text { Diş çekimi } \\
\text { sonrası } \\
\text { kanama }\end{array}$ & $\begin{array}{l}\text { En az } \\
\text { iki } \\
\text { çekimde } \\
\text { kanama yok }\end{array}$ & $\begin{array}{l}\text { Yapılmamış/ } \\
\text { bir çekimde } \\
\text { kanama yok }\end{array}$ & Bildirilmiş & $\begin{array}{l}\text { Konsültasyon } \\
\text { istenmiş }\end{array}$ & $\begin{array}{l}\text { Sütür } \\
\text { /antifibrinolitik }\end{array}$ & $\begin{array}{l}\text { Transfüzyon/replasman } \\
\text { tedavisi/desmopressin }\end{array}$ \\
\hline $\begin{array}{l}\text { Cerrahi } \\
\text { sonrası } \\
\text { kanama }\end{array}$ & $\begin{array}{l}\text { En az iki } \\
\text { cerrahide } \\
\text { kanama yok }\end{array}$ & $\begin{array}{l}\text { Yapılmamış/bir } \\
\text { cerrahide } \\
\text { kanama yok }\end{array}$ & Bildirilmiş & $\begin{array}{l}\text { Konsültasyon } \\
\text { istenmiş }\end{array}$ & $\begin{array}{l}\text { Cerrahi } \\
\text { hemostaz/ } \\
\text { antifibrinolitik }\end{array}$ & $\begin{array}{l}\text { Transfüzyon/ replasman } \\
\text { tedavisi/desmopressin }\end{array}$ \\
\hline Menoraji & - & Yok & $\begin{array}{l}\text { Konsültasyon } \\
\text { istenmiş }\end{array}$ & $\begin{array}{l}\text { Antifibrinolitik } \\
\text { /OKS }\end{array}$ & $\begin{array}{l}\mathrm{D} / \mathrm{C} \\
\text { Demir tedavisi }\end{array}$ & $\begin{array}{l}\text { Transfüzyon/ replasman } \\
\text { tedavisi/desmopressin } \\
\text { veya histerektomi }\end{array}$ \\
\hline $\begin{array}{l}\text { Postpartum } \\
\text { kanama }\end{array}$ & $\begin{array}{l}\text { İki } \\
\text { doğumda } \\
\text { kanama } \\
\text { yok }\end{array}$ & $\begin{array}{l}\text { Doğum } \\
\text { yapmamış/ } \\
\text { bir doğumda } \\
\text { kanama yok }\end{array}$ & $\begin{array}{l}\text { Bildirilmiş } \\
\text { veya } \\
\text { konsültasyon } \\
\text { istenmiş }\end{array}$ & $\begin{array}{l}\text { Antifibrinolitik } \\
\text { /OKS/D/C }\end{array}$ & $\begin{array}{l}\text { Transfüzyon/ } \\
\text { replasman teda } \\
\text { desmopressin }\end{array}$ & visi/ $\quad-$ \\
\hline $\begin{array}{l}\text { Kas } \\
\text { hematomu }\end{array}$ & - & Yok & Posttravmatik, & $\begin{array}{l}\text { Spontan } \\
\text { tedavi } \\
\text { edilmemiş }\end{array}$ & $\begin{array}{l}\text { replasman } \\
\text { tedavi } \\
\text { edilmemiş }\end{array}$ & $\begin{array}{l}\text { Cerrahi/transfüzyon } \\
\text { tedavisi/desmopressin }\end{array}$ \\
\hline Hemartroz & - & Yok & $\begin{array}{l}\text { Posttravmatik, } \\
\text { tedavi } \\
\text { edilmemiş }\end{array}$ & $\begin{array}{l}\text { Spontan, } \\
\text { tedavi } \\
\text { edilmemiş }\end{array}$ & $\begin{array}{l}\text { replasman } \\
\text { tedavisi/ } \\
\text { desmopressin }\end{array}$ & Cerrahi/ transfüzyon \\
\hline \multicolumn{7}{|l|}{ SSS } \\
\hline kanaması & - & Yok & - & - & $\begin{array}{l}\text { Subdural/ } \\
\text { herhangi } \\
\text { bir girişim }\end{array}$ & $\begin{array}{l}\text { İntraserebral herhangi } \\
\text { bir girişim }\end{array}$ \\
\hline $\begin{array}{l}\text { Diğer } \\
\text { kanamalar }\end{array}$ & - & Yok & Bildirilmiş & $\begin{array}{l}\text { Konsültasyon } \\
\text { istenmiş }\end{array}$ & $\begin{array}{l}\text { Cerrahi } \\
\text { hemostaz/ } \\
\text { Antifibrinolitik } \\
\text { /demir tedavisi }\end{array}$ & $\begin{array}{l}\text { Transfüzyon/replasman } \\
\text { tedavisi/desmopressin }\end{array}$ \\
\hline
\end{tabular}

$<150 \mathrm{mg} / \mathrm{mL}$ idi. Von Willebrand hastalığının (vWh) tanısında, vWf: Ag ve vWf: Rco için normal aralığın alt sınırları, kan grubu $O$ olanlar için $<0.40 \mathrm{iu} / \mathrm{mL}$ ve $O$ dışındaki kan grupları için $<0.50$ olarak alındı (12). En az iki kez bakılan vWf: Rco / vWf: Ag oranı $>0.6$ olan hastalar Tip-1 von Willebrand hastalığında olarak kabul edildi. 5M ürede pıhtı erime testi, FXIII eksikliğinin taranması için kullanıldı.

\section{Istatistiksel Analiz}

Tüm istatistiksel analizler IBM $®$ SPSS $®$ Statistics versiyon 25 veri analiz programı (IBM Corp. Released 2017. IBM $®$ SPSS $®$ Statistics version 25.0. Armonk, NY: IBM Corp)ileyapıldı. Tümverilerortalama \pm standart sapma (SS) ((minumum,maximum(min-max)) olarak verildi. İstatistiksel anlamlı şekilde yüksek/düşük olan sonuçlar için etki büyüklüğü (EB) cohen's d ile 
Tablo 2. Hastaların klinik ve demografik özellikleri

\begin{tabular}{|c|c|c|c|c|}
\hline & $\begin{array}{l}\text { Grup } 1 \\
\mathrm{n}: 15\end{array}$ & $\begin{array}{l}\text { Grup } 2 \\
\mathrm{n}: 62\end{array}$ & $\begin{array}{l}\text { Grup 3 } \\
\mathrm{n}: 20\end{array}$ & $\mathbf{p}$ \\
\hline Yaş (mean $\pm S D)(\min -m a x)$ & $8,5 \pm 3,0(4-15)$ & $9,5 \pm 3,8(3-17)$ & $9,9 \pm 5,7(3-17)$ & 0,62 \\
\hline \multirow[t]{2}{*}{ Cinsiyet } & 7 & 33 & 8 & 0,57 \\
\hline & 8 & 29 & 12 & \\
\hline $\mathrm{Hb}(\mathrm{g} / \mathrm{dL}) \ddagger$ & $12,9 \pm 1,1(11,1-15,1)$ & $13,1 \pm 1,4(9,1-16,9)$ & $12,9 \pm 0,9(11,2-14,8)$ & 0,62 \\
\hline PT $(s n) \S$ & $16,8 \pm 13,7(10,9-66,3)$ & $12,6 \pm 1,07(10,2-16,4)$ & $12,6 \pm 1,4(10,8-16,6)$ & 0,18 \\
\hline APTT $(s n)^{*}$ & $32,4 \pm 4,4(26,7-39,4)$ & $29,0 \pm 2,9(21,9-38,5)$ & $27,9 \pm 3,1(24,3-34,5)$ & 0,00 \\
\hline $\mathrm{BPQ}+$ & $2,5 \pm 1,1(2-6)$ & $2,1 \pm 0,4(1-4)$ & $0,00 \pm 0,0(0-0)$ & 0,00 \\
\hline
\end{tabular}

APTT: aktive parsiyel tromboplastin zamanı, BPQ: Pediatrik Kanama Anketi, Hb: hemoglobin, PT: protrombin zamanı.

hesaplandı. Frekans analizlerinde sayısal veriler yanında yüzde değerler de verildi. Verilerin dağılımı Kolmogorov-Smirnov testi kullanılarak incelendi. Grup karşılaştırmasında Student t ve grup oranlarının karşılaştırmasında ki-kare testi uygulandı. Normal dağılımı olmayan verilerin karşılaştırılmasında MannWhitney $U$ testi kullanıldı. İkiden fazla değişkenin karşılaştırılmasında Kruskal Wallis testi kullanıldı. Kruskal Wallis testi istatistiksel olarak anlamlı olanlarda iki grup arası farkı saptamak için MannWhitney $U$ testi kullanıldı. $P<0,05$ istatistiksel olarak anlamlı kabul edildi.

\section{BULGULAR}

Çalışmaya epistaksis nedeni ile konsülte edilen 77 çocuk ve 20 sağlıklı çocuk dahil edildi. Hasta ve kontrol gruplarının özellikleri Tablo 2' de gösterilmiştir. Çalışmadaki hastaların \%19,4'üne $(n=15)$ kanama diyatezi tanısı konuldu. Kanama diyatezi tanısı alan hastaların 10'unda $(\% 66,6)$ vWf eksikliği, 4'ünde $(26,6)$ FVII eksikliği ve bir hastada $(\% 6,6)$ FXI eksikliği tespit edildi. Hastaların ortalama başvuru yaşı $9 \pm 3,4$ (3-17) yıl idi. Ortalama hemoglobin düzeyleri $13 \pm 1,2(9,1-16,9) \mathrm{gr} / \mathrm{dl}$ idi. Üç $(\% 3,8)$ hastada demir eksikliği anemisi, $10(\% 12,9)$ hastada demir eksikliği tespit edildi. Kanama diyatezi tanısı alan hastalarda ortalama hemoglobin değeri kanama diyatezi olmayanlar ile benzerdi (p:0,625) (ED: 0,12). WWh tanısı alan hastaların ortalama faktör düzeyi \%32,2, nadir faktör eksikliği tanısı alanların ortalama faktör düzeyi \%26,6 idi. Sekiz hastada bir kez diş çekimi öyküsü vardı, hastaların hiçbirinde çekim sonrası anormal kanama öyküsü yoktu. Diş çekimi öyküsü olan hastalarda kanama diyatezi saptanmadı. Beş hastada bir, bir hastada iki kez ameliyat öyküsü vardı, hiçbirinde ameliyat sonrası kanama öyküsü yoktu ve kanama diyatezi tespit edilmedi. 37 kız hastanın 10'u (\%27) ergenlik döneminde idi ve hiçbirinde anormal uterin kanama öyküsü yoktu.
Von Willebrand hastalığı tespit edilen 10 hastanın 6'sı (\%60) kız, 4'ü erkekti, kızlardan 5'i (\%83) premenstruel dönemde, biri ise ergenlik döneminde idi ve anormal uterin kanaması yoktu. Von Willebrand hastalığı tanısı alan 4 erkek hastanın 3'ünde (\%75) sünnet öyküsü vardı sünnet sonrası anormal kanama olmamıştı. FXI eksikliği tanısı alan erkek hastaya sünnet yapılmamıştı. FVII eksikliği ile izlenen hastaların 2'si kız (\%50), 2'si erkekti, kızlar premenstruel dönemde idi, erkek hastalardan birine sünnet yapılmış anormal kanama görülmemişti. Hiçbir hastada kas hematomu, hemartroz, gastrointestinal (GI) sistem kanaması yoktu.

PBQ epistaksis skoru hasta grubunda sağlıklı kontrol grubuna göre istatistiksel olarak anlamlı şekilde yüksekti $(0,000)$ ancak hasta grubunda kanama diyatezi olanlar ve olmayanlar arasında istatistiksel olarak fark yoktu $(p>0,05)$. Genel skor istatistiksel olarak farklı olmamakla birlikte kanama diyatezi olan grupta daha yüksekti. Kutanöz kanama skoru kanama diyatezi olan grupta daha yüksekti ve istatistiksel olarak anlamlı fark vardı (p:0.004) (ED: 0,62). Kas içi hematom, hemartroz, SSS kanaması, sünnet sonrası kanama, makroskopik hematüri, göbek kanaması, sefal hematom açısından 3 grup arası fark yeterli pozitif skor olmadığı için değerlendirilemedi. Hastaların 12'sinde (\%16) anterior septumda laserasyon, bir hastada $(\% 1,3)$ septal deviasyon, 7 hastada (\%9) mukozada kuruluk tespit edildi. Kırk dört hastaya lokal nemlendirici tedavi verildi, 2 hastanın daha önce yapılmış koterizasyon ve tampon öyküsü vardı, vWh olan bir hastaya burun kanamasını durdurabilmek için traneksamik asit uygulandı.

\section{TARTIŞMA}

Epistaksis çocuklarda sık görülür. En sık görüldüğü yaş 2-10 yaş, ortalama başvuru yaşı ise 7-9 yaştır $(1,2)$. Beş yaş altı çocukların \%30 u, 6-10 yaş arasındakilerin \%56'sında hayatları boyunca en 
az bir kez burun kanaması görülür (3). Çalışmamızda literatür ile uyumlu olarak ortalama başvuru yaşı 9 $\pm 3,4$ (3-17) yıl idi. Sık tekrarlayan kanamalarda altta yatan kalıtsal kanama bozukluklarını araştırmak için sıklıkla hematoloji konsültasyonları istenir. Genellikle çocukluk yaş grubunda en sık görülen nedenleri travma ve inflamasyondur ancak literatürde hastaların \% 8-20'sinde altta yatan bir kanama bozukluğu tespit edilmiştir (4). En sık görülen kalıtsal kanama bozuklukluğu von Willebrand hastalığı (vWh) dır (5). Çalışmamızda hastaların \% 19,4'üne $(n=15)$ kanama diyatezi tanısı konuldu. Kanama diyatezi tanısı alan hastaların 10'unda (\%67) vWf eksikliği, 4'ünde (\%26) FVII eksikliği ve bir hastada (\%7) FXI eksikliği tespit edildi. Sonuçlarımız literatürdekiler ile benzerdi.

Kanama bozukluklarında tanıya ulaşmada detaylı ve doğru kanama öyküsü elde edilerek standardize kanama skorları geliştirilmiştir. Bunlardan biri 2009 yılında Bowman et al. (6-9) tarafından geliştirilen ve ilk kez von Willebrand hastalığı olan çocuklarda kullanılan pediatrik kanama anketi, PBQ dur. PBQ bu konuda deneyimli hekimler tarafından uygulanan bir ankettir. 2017 yılında, Casey et al. (10) hastaların ve ailelerinin yapabileceği bir kanama anketi geliştirmiş ve kanama bozukluğu araştırılması için hematoloji kliniğine sevk edilen çocuklarda von Willebrand hastalığını tanımlamak için hassas ve güvenilir bir araç olduğunu gösterilmiştir. Ancak bu çalışmaya sadece 12 yaş üzeri çocuklar alınmıştır. Bui et al. (11) 2019 yılında 8-12 yaş arası hastaların ailelerinden çok az yardım alarak uygulayabilecekleri bir anket geliştirmiş ve kanama diyatezlerinin belirlenmesinde etkin olarak kullanılabileceğini belirtmişlerdir. Ancak her iki çalışmada daha önce kanama bozukluğu olduğu bilinen ve bu nedenle takip edilen hastalarda yapılmıştır.

PBQ kanama anketi kullanılarak tip-1 von Willebrand hastalığı olan bireyler ile normal sağlıklı bireyler arasındaki kanama semptomlarını karşılaştıran çalışmalar bulunmaktadır ancak burun kanaması olan veya diğer kanama semptomları bulunan hastalarda yapılmış sınırlı sayıda çalışma bulunmaktadır. Von Willebrand hastalarında yapılan çeşitli çalışmalarda, PBQ'nun kanama hastalığı için \% 83 duyarlılığa ve \% 79 özgüllüğe sahip olduğu gösterilmiştir (9). Çalışmamızda hastalarda ortalama PBQ epistaksis skoru sağlıklı kontrol grubuna göre daha yüksekti ancak kanama diyatezi olan ve olmayan epistaksisli hastalar arasında istatistiksel olarak fark yoktu $(p>0,05)$ bunun nedeninin konsültasyon ile hematolojiye yönlendirilen ağır burun kanaması olan hastaların çalışmaya alınması olduğu düşünüldü. Menoraji, vWh olan hastalarda sıklıkla görülmektedir (13) ancak bizim vWh grubumuzda hastaların 6'sı kızdı bunlardan 5'i prepubertal dönemde idi, bunun kanama diyatezli hastaların genel skorundaki düşüklükte etkili olduğu düşünüldü.

Epistaksisli hasta grubunda kanama diyatezi olanlar ve olmayanlar arasında epistaksis skoru arasında anlamlı bir fark yoktu ancak genel skor istatistiksel olarak farklı olmamakla birlikte kanama diyatezi olan grupta daha yüksekti. Kutanöz kanama skoru kanama diyatezi olan grupta daha yüksekti ve fark istatistiksel olarak anlamlı idi (p:0,004) (ED:0,62). Epistaksis dışındaki skorlara bakıldığında kanama diyatezi olan grupta literatürle uyumlu skor yüksek bulunmuştur (9). Burun kanaması şikayeti ile başvuran hastalarda detaylı bir kanama öyküsü alınması ve kanama anketleri kullanılması kanama bozukluğu olan hastaları sağlıklı çocuklardan ayırmada yardımcı olabilir. Çalışmamızda burun kanaması ile başvuran ve kanama diyatezi tespit edilen grupta kutanöz kanama skorları anlamlı olarak yüksek bulundu buda ayrıntılı kanama öyküsünün kanama diyatezi tanısında ki önemini göstermektedir.

Bu çalışma, birinci basamak sağlık kuruluşlarına başvuran epistaksisli hastalarda pediatrik kanama anketinin kullanılabileceğini ve epistaksis skorları arasında fark olmasada yüksek genel skor ve kutanöz kanama skorlu hastalardan ileri araştırmalar için hematoloji konsültasyonu istenmesi gerektiğini göstermiştir.

Çıkar Çatışması: Çalışmada herhangi bir çıkar çatışması yoktur.

Finansal Çıkar Çatışması: Çalışmada herhangi bir finansal çıkar çatışması yoktur.

Yazışma Adresi: Nergiz Öner, Sağlık Bilimleri Ünüversitesi, Dr. Sami Ulus Kadın Doğum, Çocuk Sağlığı ve Hastalıkları Eğitim ve Araştırma Hastanesi, Çocuk Hematoloji ve Onkoloji, Ankara, Türkiye

Telefon: 03123056166

e-mail: nbattaloglu@yahoo.com

\section{KAYNAKLAR}

1. Davies K, Batra K, Mehanna R, et al. Pediatric epistaxis: Epidemiology, management \& impact on quality of life. Int J Pediatr Otorhinolaryngol 2014;78:1294-7.

2. Shay S, Shapiro NL, Bhattacharyya N. Epidemiological characteristics of pediatric epistaxis presenting to the emergency department. Int J Pediatr Otorhinolaryngol 2017;103:121-4.

3. Record S. Practice guideline: Epistaxis in children. J Pediatr Health Care 2015;29:484-8.

4. Gifford TO, Orlandi RR. Epistaxis. Otolaryngologic Clinics of 
North America 2008;41:525-36.

5. Nichols WL, Hultin MB, James $A H$,et al. Von Willebrand disease (VWD): Evidence-based diagnosis and management guidelines, The National Heart, Lung, and Blood Institute (NHLBI) Expert Panel Report (USA). Haemophilia 2008;14:171-232.

6. Bidlingmaier $\mathrm{C}$, Grote V, Budde $\mathrm{U}$, et al. Prospective evaluation of a pediatric bleeding questionnaire and the ISTH bleeding assessment tool in children and parents in routine clinical practice. J Thromb Haemost 2012;10:1335-41.

7. Rodeghiero F, Tosetto A, Abshire T, et al. Perinatal/Pediatric Hemostasis Subcommittees Working G. ISTH/SSC bleeding assessment tool: A standardized questionnaire and a proposal for a new bleeding score for inherited bleeding disorders. J Thromb Haemost 2010;8:2063-5.

8. Tosetto A, Castaman G, Plug I, et al. Prospective evaluation of the clinical utility of quantitative bleeding severity assessment in patients referred for hemostatic evaluation. $J$ Thromb Haemost 2011;9:1143-8.
9. Bowman $\mathrm{M}$, Riddel $\mathrm{J}$, Rand $\mathrm{ML}$, et al. Evaluation of the diagnostic utility for von Willebrand disease of a pediatric bleeding questionnaire. J Thromb Haemost 2009;7:1418-21.

10. Casey LJ, Tuttle A, Grabell J, et al. Generation and optimization of the self-administered pediatric bleeding questionnaire and its validation as a screening tool for von Willebrand disease. Pediatr Blood Cancer 2017;64:265-88.

11. Bui J, Martyres D, James PD, et al. Validation of the school age self-administered pediatric bleeding questionnaire (SelfPBQ) in children aged 8-12 years. Pediatr Blood Cancer 2019;66:27709.

12. Nichols WL, Hultin MB, James $A H$, et al. Von Willebrand disease (VWD): Evidence-based diagnosis and management guidelines, the National Heart, Lung, and Blood Institute (NHLBI) Expert Panel report (USA). Haemophilia 2008;14:171-232.

13. James $\mathrm{AH}$. Women and bleeding disorders. Hemophilia 2010;16:160-7. 